\title{
Erratum
}

\section{Hydrogeologic controls of surface-water chemistry in the Adirondack region of New York State}

\section{N.E. PETERS ${ }^{1}$ \& C.T. DRISCOLL ${ }^{2}$}

${ }^{1}$ US Geological Survey, Water Resources Division, Doraville, GA 30360, USA

${ }^{2}$ Department of Civil Engineering, Syracuse University, Syracuse, NY 13210, USA

Biogeochemistry 3: 1-3, 1987 (p. 165)

Special issue: Acidification of the Moose River system in the Adirondack Mountains of New York State

In Fig. 1 on page 165 the labels were reversed. Below can be found the correct version of the Figure.

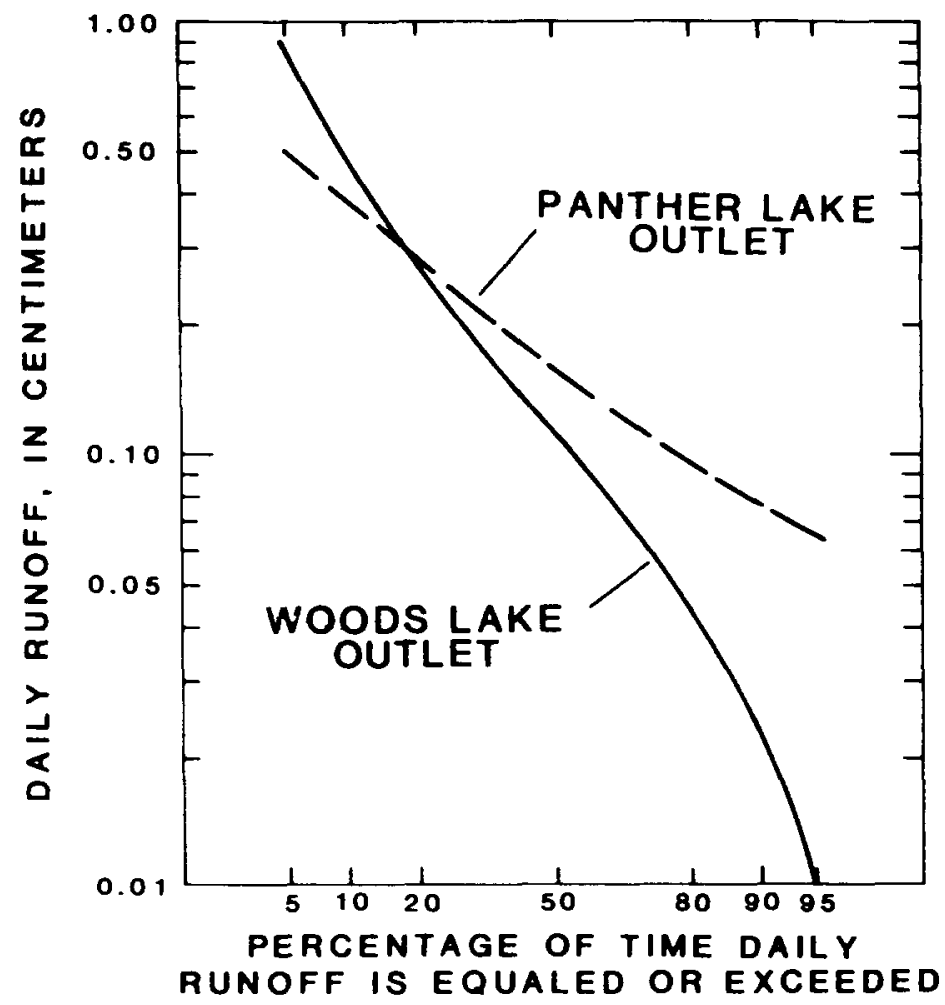

Fig. 1. Flow-duration curves for daily runoff from acidic Woods and neutral pH Panther Lakes, January 1980 through December 1981. 